\title{
Dentistry and the social media
}

\author{
A midia social na odontologia
}

César Antonio PEREIRA'

\section{ABSTRACT}

\section{Objective}

The aim of this study was to hence the quest for an understanding of the theoretical and empirical foundations of studies of social media within Dentistry Science. In particular, it has been sought to identify the temporal and thematic behaviors of studies concerning social media in Dentistry.

\section{Methods}

It involves an exploratory study of the bibliometrics and scientometrics, using a quali-quantitative approach. The universe is made up of the scientific production concerning the social media contained in articles related to the area, indexed in the Web of Science. In order to understand the objects of the studies identified, content analysis was employed.

\section{Results}

The results enabled us to map the profile of the temporal and thematic behavior of the studies developed, localizing the period of publication, areas of knowledge with production that is related to Dentistry Science and the issues occurring most frequently.

\section{Conclusion}

Given the complexity of the topic, a more profound epistemological and pragmatic approach is envisioned for future production.

Indexing terms: Bibliometric studies. Dentistry. Scientometric studies. Social media.

\section{RESUMO}

\section{Objetivo}

Identificar os comportamentos temporal e temático dos estudos sobre mídia social na Odontologia.

\section{Métodos}

Constitui-se em estudo bibliométrico e cientométrico de caráter exploratório com abordagem quali-quantitativa. O universo é composto pela produção científica sobre mídia presente nos artigos da área, indexados na Web of Science. Para a compreensão dos objetos dos estudos identificados, utilizou-se análise de conteúdo.

\section{Resultados}

Os resultados permitiram traçar perfil do comportamento temporal e temático dos estudos desenvolvidos, situando o período de publicação, áreas do conhecimento com produção correlacionadas à Odontologia e assuntos com maior ocorrência.

\section{Conclusão}

Dada a complexidade que a temática requer, vislumbra-se maior aprofundamento epistemológico e pragmático para futuras produções.

Termos de indexação: Bibliometria. Odontologia. Cientometria. Mídia sociais.

\footnotetext{
1 Pontifícia Universidade Católica de Campinas - PUC Campinas, Programa de Pós-Graduação em Linguagens, Mídia e Arte. Rod. D. Pedro I, km 136, Pq. das Universidades, 13086-900, Campinas, SP, Brasil. Correspondência para / Correspondence to: CA PEREIRA. E-mail: <cesarpereira@puc-campinas.edu.br>.
} 


\section{INTRODUCTION}

Social media platforms have been widely used as tools for publishing a variety of content on the web. Using social media, it is possible, among other things, to establish relationships with other people with similar interests. According to Barbosa ${ }^{1}$, the media communications model presents information in an interactive way, as it permits direct, immediate participation; it is a more personalized form of interaction with the possibility of active selection of content; it is recorded and documented, by virtue of navigation or hypertext links and relationship updates, bearing in mind that the dynamics of news and information alter the concept of periodicity; it encompasses all production formats: text, audio, video, graphs, photographs, constituting multimedia; it applies execution steps in sequence and in a usable and accessible format, principally to help the reader to navigate.

On the other hand, significant changes can be observed in the landscape of communication media as strategic tools. A repositioning has taken place in terms of the production of content, of changes in work routines, support, distribution infrastructure and business models ${ }^{2}$. For Jenkins ${ }^{3}$, these structures help to create a "convergence culture", in which the broad separation between creators of content and their audiences has become blurred.

In the area of healthcare, in addition to great interactivity based on discussion groups, social media affords closer personal contact and cooperation between users and organizations, resulting in a greater exchange of content and experiences ${ }^{4}$. Moreover, the publication and sharing of content in the area of healthcare makes it easier to use social media as a source of information in the quest for greater understanding of the gaps that exist in this area.

The central reasoning is that the means of media communication do not only serve to communicate information to individuals. They also condition and regulate new formats and strategies for information interaction and action in society, new social relationships, whether it be by the individuals with the world or the individuals with themselves ${ }^{5}$.

Despite the importance of these reflections on social media, the uses and users of information, of media content and the relationship of healthcare to the topic, scientific production in the area of Dentistry on social media and the information strategies in the practice of research, remain relatively unknown. Little is known about the use of social media in Dentistry in light of the studies that have been conducted, its relationship and aspects of ownership with other fields and areas of knowledge, which theoretical and empirical topics and objects have oriented studies on the topic.

Therefore, it is sought to understand the theoretical and empirical bases of studies into social media in Dentistry, seeking to contribute with scientific observations. Specifically, the aim is to identify behavior of a temporal, authorial, thematic and content nature in the studies published on social media in Dentistry.

The understanding of the current scenario regarding the use of these studies makes it possible to look for ways to improve and incorporate alternatives that will make it possible to supplement them with information from cognitive and social contexts of scientific activity practiced by those involved in dentistry. With the panorama of studies on social media in Dentistry, it is hoped to contribute to a critical reflection that will lead to its improvement and to more adequate conditions of administrative management and research practices concerning the topic of social media in the area.

\section{METHODS}

This is an exploratory study with a qualiquantitative approach. The body of analysis is made up of scientific articles published in journals indexed in the Web of Science (WoS) international database, in the area of Dentistry (Dentistry Oral Surgery Medicine).

The WoS is regarded as one of the main sources of scientific and technological information. The coverage of existing journal titles in the database undergoes constant revision in order to ensure that the titles are of great relevance to the scientific community. All the journals are analyzed in terms of both quality and quantity. The journal data are correlated and interrelated, giving the editor a certain assurance and comfort that both the strong points and weak points of the journal have been established ${ }^{6}$. By virtue of this scenario, the WoS is recognized as a source that provides high-quality information in the fields of science and technology, as the diligence with which the indexed journals are evaluated ascribes this quality.

The search for articles on the WoS was conducted following a number of steps advocated by Lopes? ${ }^{7}$. The following keywords, translated into English, were used: "social media"; "dentistry". The search was carried out using Boolean logic (words combined using AND and OR) 
and/or truncation operators (words combined using '?' or '*', used to retrieve words based on prefixes or suffixes). The entire period covered by the database was considered.

The studies thus identified were organized and measured based on Information Metrics Studies, specifically through the specialties of bibliometrics and scientometrics, the metric measurement branches of scientific and technological publications. To this end, Bibexcel software was used to extract and measure the data. To perform a graphical representation of the results, the programs Microsoft Excel, Ucinet/Netdraw and Nuvem de Palavras (http://www.wordle.net/create) were used to represent the keywords of the published studies.

By using Bibexcel, it was possible to produce quantitative indicators of scientific productivity from the variables and fields of the identified studies, namely: Temporal: delimitation of the historical evolution of production, journals, authors with publications on the topic of social media in dentistry and keywords; - Topics: delimitation of areas of knowledge, of research activities and relationships between areas and subject matter.

With the aim of identifying content that would provide support for the understanding of studies produced on social media in the area of Dentistry, an analysis of the content of the studies was performed ${ }^{8}$ to delineate the knowledge domains and theoretical objects addressed. They were performed in the context of keywords or titles, abstracts, objectives or body of the text, reading and analysis of the content of the studies. This analysis permitted the identification of works for which the object of the study or analysis was social media in the area of Dentistry.

\section{RESULTS AND DISCUSSION}

A total of 41 studies were located in respect of social media in Dentistry, indexed on the Web of Science database. In light of the studies identified, indicators of scientific production and of content were organized.

\section{Indicators of Scientific Production: temporal, authorial and thematic cross-section}

The temporal cross-section analyzed encompasses only 6 years (2011-2016). The distribution is characterized by a marked representativeness in the number of published studies, particularly over the course of the last three years (Figure 1).

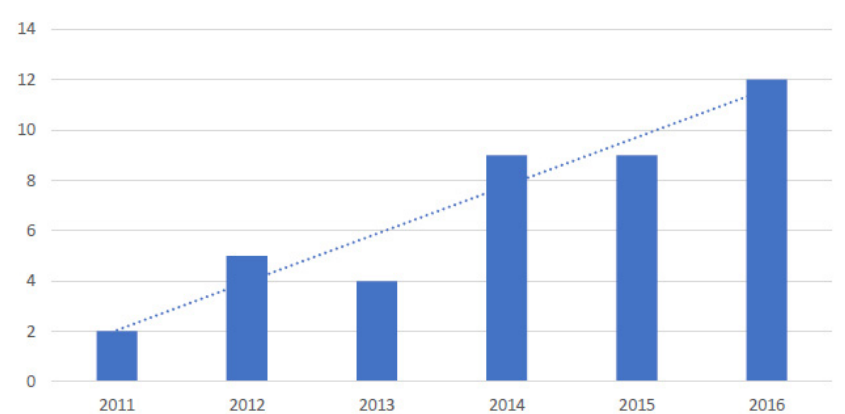

Figure 1. Time progression of studies into social media, published on the Web of Science database (2011-2016) in the area of Dentistry.

All the studies published are from 2010 onwards, with 2011 marking the start of studies into social media in Dentistry, when 2 studies were produced. At this time, scientific production was not particularly representative, although there was a certain relevance to the topic in this area. The period is identified as marking the beginning of studies on the topic, using the Web of Science.

In 2012 and 2013, a growth in the number of studies can be observed, with $26 \%$ of the total studies published. Between 2014 and 2016, 30 studies were identified, or approximately $70 \%$ of the total number of studies published over the entire period. The year 2016 stood out as the most representative year, at $29 \%$. In recent years, an exponential growth has been seen in the number of studies published on social media in Dentistry.

The decade commencing 2010 is notable for the significant number of studies produced. In this period, 2011 to 2016 , the social media topic has not only strengthened but has gained something of a reputation in academic circles. Therefore, year on year, a sharp growth has been seen in the number of studies, characterizing the period not only as the most significant, but also as a milestone marking the beginning of topics in the area of Dentistry.

Over the course of the period of the review, in addition to Dentistry, a further four areas of study were identified, with a significant concentration of studies published on social media, regarding the respective areas (Table 1).

Table 1. Areas of knowledge with studies related to Dentistry on social media, published in the Web of Science database (2011-2016).

\begin{tabular}{lll}
\hline Areas of Study & Studies & $\%$ \\
\hline Dentistry, Oral Surgery \& Medicine & 41 & 100 \\
Education \& Educational Research & 2 & 4.8 \\
Pediatrics & 2 & 4.8 \\
Public, Environmental \& Occupational Health & 1 & 2.4 \\
Surgery & 1 & 2.4 \\
\hline
\end{tabular}


Regarding the knowledge domains of the published works, a relationship was observed between the field of Dentistry and other fields, in particular, with just six studies, or $14 \%$ of the total. Of the 4 areas identified as having a productive relationship with studies into social media in Dentistry, the following are the most prominent: "Education \& Educational Research" and "Pediatrics", with $4.8 \%$ and each with 2 published studies, and "Public,
Environmental \& Occupational Health " and "Surgery", each with 1 published study and a representation of $2.4 \%$, respectively.

The determination of the quality of the published studies is a preeminent factor in the area, as they are publications in renowned dental journals. In total, 15 journal titles were identified with publications about social media in the area (Figure 2).

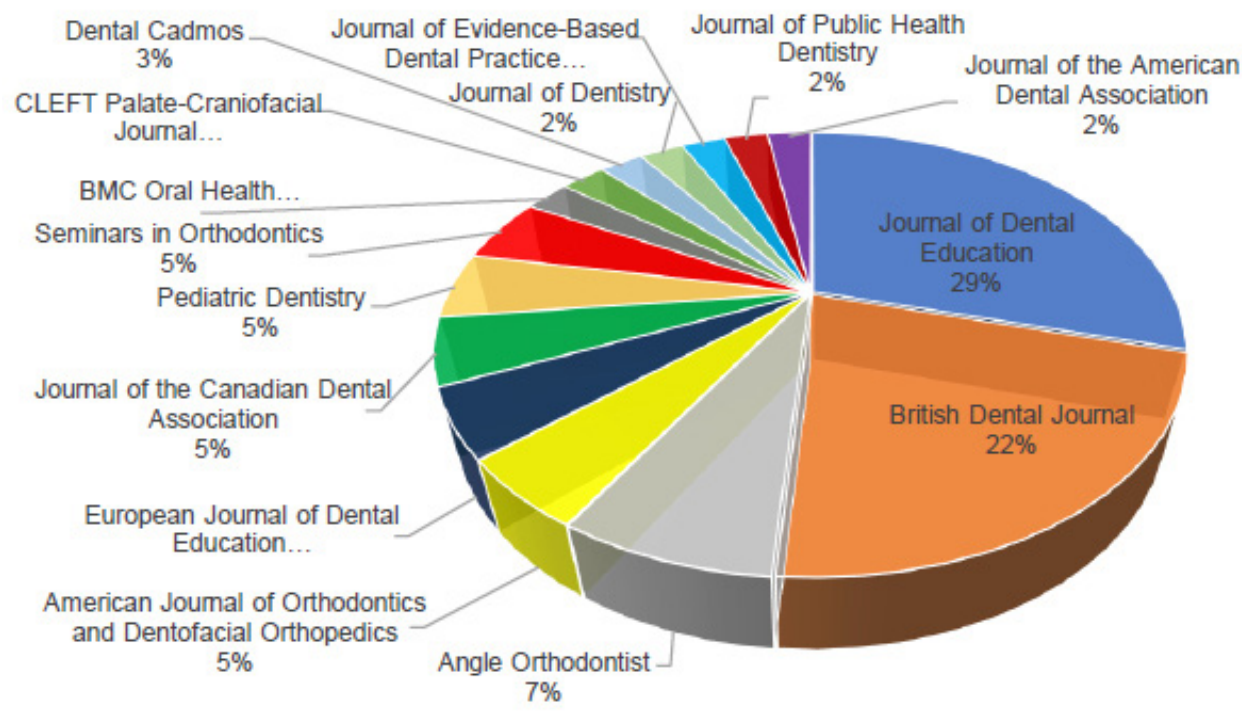

Figure 2. Scientific journals addressing social media in Dentistry, published on the Web of Science database (2011-2016).

Special mention is reserved for the "Journal of Dental Education", "British Dental Journal" and "Angle Orthodontist" with a total of 24 published studies and approximately $58 \%$ of the total number of studies into social media in Dentistry. Other journals were responsible for a total of 10 published studies on the topic, representing $24 \%$ of the total, primarily in the following publications: "American Journal of Orthodontics and Dentofacial Orthopedics"; "European Journal of Dental Education"; "Journal of the Canadian Dental Association"; "Pediatric Dentistry" and "Seminarsin Orthodontics", with two published studies in each journal. Lastly, seven journals published just 1 study each, namely: "BMC Oral Health"; "CLEFT Palate-Craniofacial Journal"; "Dental Cadmos"; "Journal of Dentistry"; "Journal of Evidence-Based Dental Practice"; "Journal of Public Health Dentistry" and "Journal of the American Dental Association".

All the journals containing output related to social media and Dentistry are of very high quality on the world stage. This observation is, strictly speaking, down to the procedures adopted by the Web of Science (WoS), the source of data for the present study. The WoS analyzes the indexed journals by means of citations in the scientific community and, consequently, establishes the Impact Factor and the standardization of quality, compared to other reviews in the same field of knowledge. The effect of this structure elicits quality in the topics addressed in the studies and a high level of credibility with the information organization processes. As a result, it has become a significant source of information for the understanding of knowledge domains.

In addition, a total of 127 authors were identified in the 41 studies on the topic of social networks in dentistry. The analysis of the distribution of studies, by author, reveals a high dispersal, by virtue of the $88.98 \%$ of authors with only one publication. The core, in turn, reveals a concentration of few authors, specifically 14 authors with two or more publications on the topic, representing $22.66 \%$ of the total number of authors identified. In this context, we would highlight: "Spallek, $H$ " with 4 studies; "Knosel, M"; "McAndrew M" and "Turner, S.P." with 3 studies each; "Arnett, M.R."; "Bleckmann, 
A."; "Chambers, D."; "Donate-Bartfield, E."; "Gao, X.L."; "Henry, R.K."; "Jung, K."; "Karimbux, N."; "O'Donnell, J.A."; "Zarkowski, P", each having two studies published.

The list of authors with sources used in the publication of scientific results on social media and dentistry, demonstrates that the "Journal of Dental Education" has been one of the main means of communication of science developed on the topic of social networks. Of the total number of authors with more than one publication, 92.85\% have articles in this journal. The two studies published by "Gao, X.L." differ from the rest in terms of the source for publication inasmuch as the author only makes use of "Journal of Dentistry" and "Pediatric Dentistry" (Figure 3).
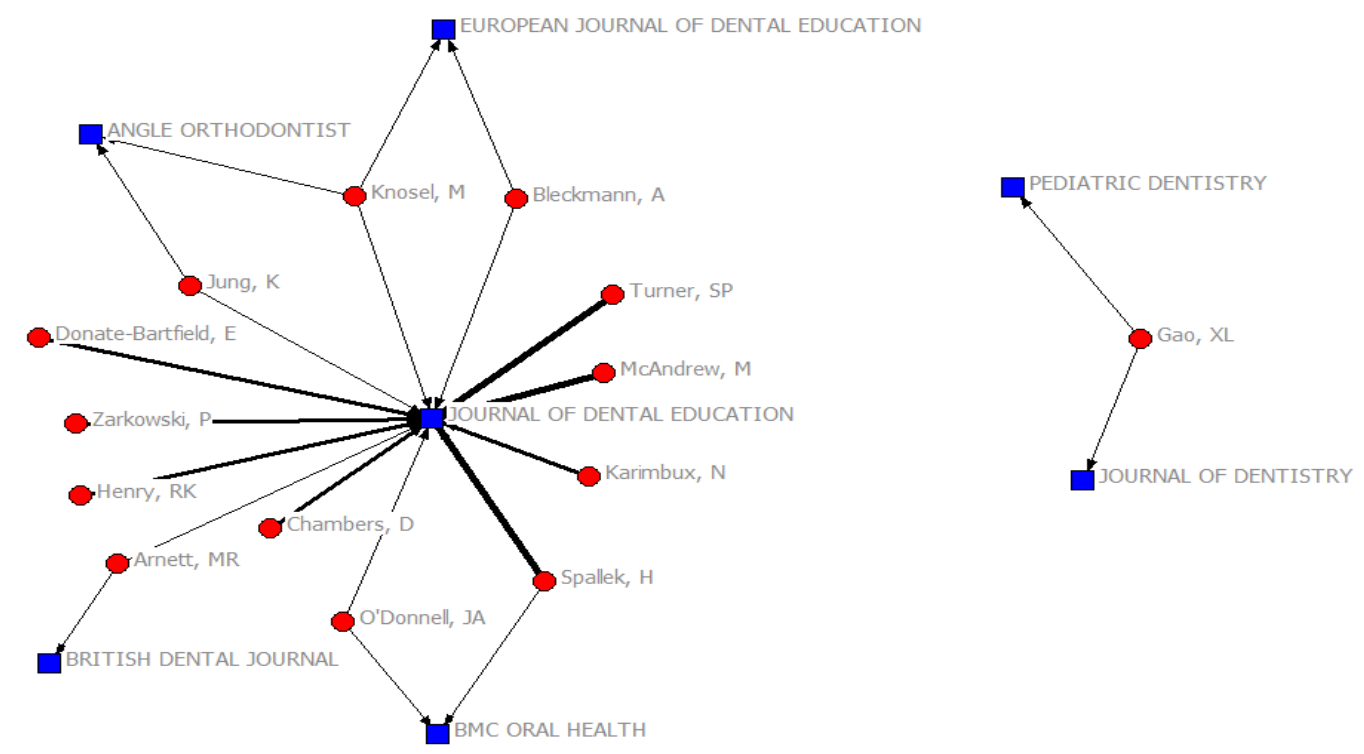

Figure 3. Scientific journals on social media in Dentistry, published on the Web of Science database (2011-2016).

Among the topics developed in the area of Dentistry concerning social media, observed based on keywords used by the authors of the studies, the most prominent are those related to the understanding of the impact of information relationships established by the media, particularly social media, to the media communication technologies and platforms and to the educational impacts of this structure in clinical environments and professional qualification in dentistry. Of the 101 keywords identified, 16 appear more than once in the grand total of studies.

The keywords "social media" and "dental education" are the most prominent. Together, they represent $17.9 \%$ of the total number of keywords identified. "Educational Technology", "Web 2.0" and "Technology" are also conspicuous, with $8 \%$ of the total number of keywords (Figure 4).

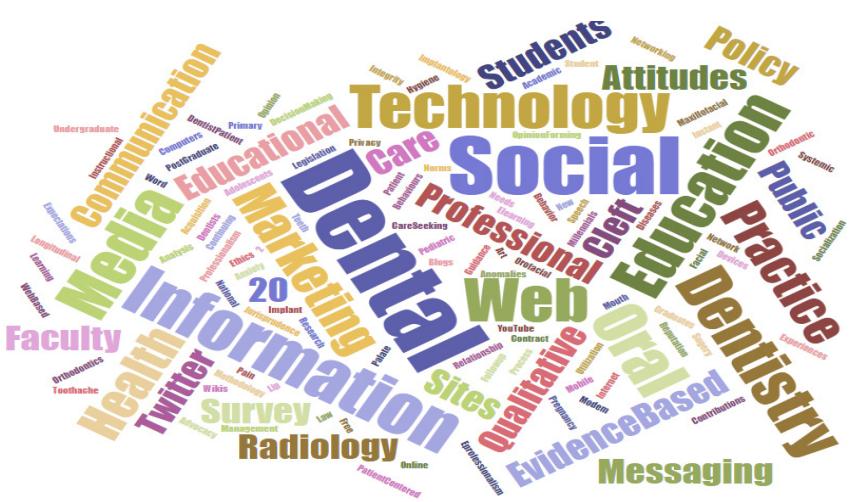

Figure 4. Keywords used in studies about social media in Dentistry, published in indexed reviews on the Web of Science database (2011-2016).

Other keywords exhibit a distribution that is greater than or equal to 2 studies each, the most frequent being: "dental students"; "information management"; "legislation and jurisprudence"; "oral health"; "pediatric dentistry"; "privacy"; "professional ethics"; "professionalism"; "qualitative research"; "twitter" and "youtube". Each of these keywords represents research study interest in social media in the area of dentistry. There 
is, therefore, a need to reflect on the educational impact on the training of the professional dentist.

\section{Analysis of content}

The identification of the research study objects, in light of the analysis of content, enabled the observation of the theoretical and empirical objects of the studies into social media in Dentistry. The organization of the study topics reveals theoretical objects conditional upon the understanding and impacts of social media on education and the professional practice of the dentist.

The initial studies ${ }^{9-10}$ into media and dentistry broadcast the value and relevance of the information communicated across social networks, particularly on the Youtube platform. The forms of interaction with the subjects, the intent of the message, the search for and perspective of the content formed the thrust of the objects of analysis. To this end, the videos made available on the platform were analyzed in order to investigate and understand the potential uses of social media in the area.

Other studies explored the scope of social media provided by other platforms such as Facebook and Twitter. To understand the modes of socialization for learning and education in dentistry, potential problems and obstacles to implementation of pedagogic models for the training of the dental professional, awareness of oral health via messages directed to pregnant women and analyses of the impact of social media using film published on the networks, reflected the studies' main interests. On the other hand, studies were observed related to the description of strong points, weak points, risks and opportunities inherent in the use of social platforms, analytical methods and tools ${ }^{11-12}$.

The greater involvement of scientific academia was observed with the use of social media as potential objects for analysis. To this end, studies were undertaken, applied by members of the teaching staff of Institutions of Dental Education and Research with the aim of identifying the main social media platforms used, both by the academic community and by dental patients. Importantly, studies were identified that were dedicated to understanding the changes in dental education given the intensive use of social media, particularly by students, resident dentists and lecturers, the relationship between the lack of literacy and the digital comfort of students, aimed at supporting educational discussions on the qualification of dentists. Additionally, one study was identified with regard to the policies, violations and recommendations for the use of social networks in dental colleges. Lastly, a number of studies addressed the elaboration of the curriculum involving the teaching and learning on social networks in dental education. The greatest concern was with the educational preparation of future generations in the academic community, leading them to understand the limitations of discourse produced by social media platforms ${ }^{13-20}$.

Studies on the role of social media in the professionalism of the dentist were also highlighted. Concurrently, other studies raised discussions about the professionalization of the use of social media by the dentist, the effectiveness of communication, education of patients, their perceptions and attitudes with regard to connectivity, as well as studies concerning treatment experiences, ethical skills, standards of professional practice, access, quantity and type of content in social platform profiles, plus studies aimed at getting to know professional profiles of patients, dimensioning tooth pain caused by dental surgery, all of which are published on social media. Other studies explored the various ways in which social networks can not only help but also hinder the practice and professionalism of the dentist. These instances addressed intensity of pain, actions taken and the cause and effect relationship. Given the rich source of information available on social media, some studies explored the perspectives of on the management of dental fear and anxiety in pediatric patients ${ }^{21-30}$.

In essence, as the number of studies on social media rise significantly, Dentistry finds itself involved with the impact and interference caused by these studies, particularly from an educational and professional perspective, in terms of understanding the modes of information mediation via socially collaborative platforms. Therefore, one can witness the attention paid to usage formats, behavior and users of information, aiming to perfect the models of educational management and professional practices, improvement in business, products and services.

The exercise of the analyzed study is accentuated in the decade commencing 2010, and particularly in the later years. The exponential growth in the number of published works on the topic reflects the variety of study topics covered with little compatibility with other areas of knowledge. The recognition of the role of digital social media, as well as the nuances of its applications and representations in the context of production, representation and publication of information, assume greater importance in the contemporary context of the area. In light of this observation, the number of researchers and channels of 
scientific publication is demonstrated, particularly based on the dispersion of the keywords used to represent the content of the documents.

\section{CONCLUSION}

As far as the study objects are concerned, the development of topics related to the theoretical and empirical understanding of social media in the educational and professional practice of Dentistry can be observed.

\section{REFERENCES}

1. Barbosa S. Jornalismo digital de terceira geração. Covilhã: Universidade da Beira Interior; 2007.

2. Casero-Ripollés A. Más allá de los diários: el consumo de noticias de los jóvenes en la era digital. Comunicar. 2012;20(39):151-58.

3. Jenkins H. Cultura da convergência. $2^{a}$ ed. São Paulo: Aleph; 2009.

4. Antunes MN. Monitoramento de informação em mídias sociais: o e-Monitor Dengue. Transinformação. 2014;26(1):9-18.

5. Thompson JB. A mídia e a modernidade: uma teoria social da mídia. Petrópolis: Vozes; 1998.

6. Testa J. A base de dados ISI e seu processo de seleção de revistas. Ciênc Inform. 1998:27(2):233-5.

7. Lopes IL. Estratégia de busca na recuperação da informação: revisão da literatura. Ciênc Inform. 2002;31(2):60-71.

8. Bardin L. Análise de conteúdo. Lisboa: Edições 70; 1977.

9. Knoesel $M$, Jung $K$, Bleckmann $A$. You Tube, dentistry, and dental education. J Dental Educ. 2011;75(12):1558-68.

10. Knoesel M, Jung K. Informational value and bias of videos related to orthodontics screened on a video-sharing Web site. Angle Orthod. 2011;81(3):532-39. doi: 10.2319/091710-541.1

11. Rachel Henzell M, Margaret Knight A, Morgaine KC, Antoun JS, Farella M. A qualitative analysis of orthodontic-related posts on Twitter. Angle Orthod. 2014 Mar;84(2):203-7. doi: 10.2319/051013-355.1.

12. Ahlwardt K, Heaivilin N, Gibbs J, Page J, Gerbert B, Tsoh JY. Tweeting about pain: comparing self-reported toothache experiences with those of backaches, earaches and headaches. J Am Dent Assoc. 2014 Jul;145(7):737-43. doi: 10.14219/ jada.2014.30.

13. Knösel M, Engelke W, Helms HJ, Bleckmann A. An appraisal of the current and potential value of web 2.0 contributions to continuing education in oral implantology. Eur J Dent Educ. 2012 Aug;16(3):131-7. doi: 10.1111/j.1600-0579.2011.00732.x

14. McAndrew $\mathrm{M}$, Johnston AE. The role of social media in dental education. J Dent Educ. 2012 Nov;76(11):1474-81.

15. Arnett MR, Loewen JM, Romito LM. Use of social media by
The interaction between the various components in the process of creating knowledge, particularly from social networking platforms, has resulted in the continuous creation of information and knowledge, core investments for the increase in learning and innovation. The field of Dentistry seems to be accompanying this trend. However, given the complexity of the topic, it is possible to envision a more profound epistemological and pragmatic approach involving future output on social media, in the area of Dentistry.

dental educators. J Dent Educ. 2013 Nov;77(11):1402-12

16. Parkinson JW, Turner SP. Use of social media in dental schools: pluses, perils, and pitfalls from a legal perspective. J Dent Educ. 2014 Nov;78(11):1558-67

17. Arnett MR, Christensen HL, Nelson BA. A school-wide assessment of social media usage by students in a US dental school. Br Dent J. 2014 Nov;217(9):531-5. doi: 10.1038/sj.bdj.2014.956

18. Spallek H, Turner SP, Donate-Bartfield E, Chambers D, McAndrew $M$, Zarkowski $P$, et al. Social media in the dental school environment, Part A: benefits, challenges, and recommendations for use. J Dent Educ. 2015 Oct;79(10):1140-52

19. Gonzalez SM, Gadbury-Amyot CC. Using Twitter for teaching and learning in an oral and maxillofacial radiology course. J Dent Educ. 2016 Feb;80(2):149-55

20. Macluskey M, Shepherd S, Carter E, Bulsara Y, Durham JA, Bell $A$, et al. A national follow-up survey of UK graduates opinion of undergraduate oral surgery teaching. Eur J Dent Educ. 2016 Aug;20(3):174-9. doi: 10.1111/eje.12158.

21. Glaizel J. Plugged in: social media in the dental profession. J Can Dent Assoc $2013 ; 79:$ d148

22. Song M, O'onnell JA, Bekhuis T, Spallek H. Are dentists interested in the oral-systemic disease connection? A qualitative study of an online community of 450 practitioners. BMC Oral Health. 2013;13:65. doi: 10.1186/1472-6831-13-65

23. Hamzah HS, Gao X, Yung Yiu CK, McGrath C, King NM Managing dental fear and anxiety in pediatric patients: $A$ qualitative study from the public's perspective. Pediatr Dent. 2014 Jan-Feb;36(1):29-33

24. Neville $P$, Waylen $A$. Social media and dentistry: some reflections on e-professionalism. Br Dent J. 2015 Apr 24;218(8):475-8. doi: 10.1038/sj.bdj.2015.294

25. Parsons CF, Breckons M, Durham J. Twitter: a viable medium for daily pain diaries in chronic orofacial pain? $\mathrm{Br}$ Dent J. 2015;219(2):75-8. doi: 10.1038/sj.bdj.2015.558

26. Al-Silwadi FM, Gill DS, Petrie A, Cunningham SJ. Effect of social media in improving knowledge among patients having fixed appliance orthodontic treatment: A single-center randomized controlled trial. Am J Orthod Dentofacial Orthop. 2015 Aug;148(2):231-7. doi: 10.1016/j.ajodo.2015.03.029

27. Nelson KL, Shroff B, Best AM, Lindauer SJ. Orthodontic marketing through social media networks: the patient and 
practitioner's perspective. Angle Orthod. 2015 Nov;85(6):103541. doi: 10.2319/110714-797.1

28. Migliorati M. Effective communication in dentistry in the new media era. Dental Cadmos. 2016;84(1):16-29.

29. Seymour B, Yang H, Getman R, Barrow J, Kalenderian E. Patientcentered communication: exploring the dentist's role in the era of e-patients and health 2.0. J Dent Educ. 2016 Jun;80(6):697704.
30. Kenny P, Johnson IG. Social media use, attitudes, behaviours and perceptions of online professionalism amongst dental students. Br Dent J. 2016 Nov 18;221(10):651-655. doi: 10.1038/ sj.bdj.2016.864

Received on: 25/5/2017

Final version resubmitted on: 26/6/2017

Approved on: 30/6/2017 